\title{
Synaptic Responses Evoked by Mechanical Stimulation of the Mucosa in Morphologically Characterized Myenteric Neurons of the Guinea-Pig lleum
}

\author{
J. C. Bornstein, ${ }^{1}$ J. B. Furness, ${ }^{2, a}$ T. K. Smith,, ${ }^{2, b}$ and D. C. Trussell ${ }^{2}$ \\ Centre for Neuroscience and Departments of Physiology and of ${ }^{2}$ Anatomy and Histology, Flinders Medical Centre, \\ Bedford Park, South Australia, 5042, Australia
}

\begin{abstract}
Recordings were made from myenteric neurons of the guinea-pig ileum during reflexes evoked by mechanical stimulation of the mucosa. Impaled neurons were injected with dye (Lucifer yellow or biocytin), and their shapes were determined. All neurons were 5-12 $\mathrm{mm}$ from the stimulus, a brush stroke that deformed the mucosal villi. Neurons were classified as S-neurons or AH-neurons (Hirst et al., 1974). About $40 \%$ of S-neurons oral to a stimulus responded with bursts of fast EPSPs (average frequency, 15-40 Hz); these neurons were in ascending reflex pathways. About $60 \%$ of S-neurons anal to a stimulus responded with similar bursts of fast EPSPs or slow depolarizations; these neurons were in descending pathways. Only 2 of $48 \mathrm{AH}$-neurons responded, both in descending pathways. Most S-neurons in either ascending or descending pathways received inputs from at least 2 or 3 other neurons. Action potentials evoked during a response averaged $3-10 \mathrm{~Hz}$ in frequency, with occasional bursts at up to $100 \mathrm{~Hz}$. The speed of conduction along the reflex pathways was about $0.5 \mathrm{~m} / \mathrm{sec}$. All S-neurons were uniaxonal, but they differed in size, dendritic morphology, and projections. The axons of S-neurons injected with biocytin were followed up to $7 \mathrm{~mm}$ within the myenteric plexus. Three S-neurons projected to the tertiary plexus and were probably longitudinal muscle motor neurons; 2 of these were in descending pathways. Five S-neurons projected along the intestine and had varicose collaterals in some ganglia. These neurons were probably interneurons; 3 were descending and 2 ascending, and all responded in the appropriate reflex pathway. Many S-neurons had short axons that entered the circular muscie and were probably clicular muscle motor neurons. Others projected several millimeters along the intestine before entering the circular muscle or fading beyond detection. From this study, we have been able to deduce the circuits mediating ascending and descending mucosa-to-
\end{abstract}

\footnotetext{
Received June 19, 1990; revised Sept. 18, 1990; accepted Sept. 26, 1990.

We thank Mrs. Janine Edwards and Mrs. Cheryl Turner for expert technical assistance and Mr. Rudolph Danz and Mr. Brian Bridger for construction of the mechanical stroker. This work was supported by a grant from the National Health and Medical Research Council of Australia.

Correspondence should be addressed to Dr. J. C. Bornstein, Physiology Department, University of Melbourne, Parkville, Victoria 3052, Australia.

Present address: Department of Physiology, University of Melbourne, Parkville, Victoria 3052, Australia.

b Present address: Department of Physiology, University of Nevada School of Medicine, Reno, NV 89557-0046.

Copyright (C) 1991 Society for Neuroscience $0270-6474 / 91 / 110505-14 \$ 03.00 / 0$
}

muscle reflexes. It is concluded that AH-neurons are primary sensory neurons and S-neurons are interneurons and muscle motor neurons in the circuits.

Although peristaltic reflexes were described in the 1800 s (Nothnagel, 1882; Mall, 1896; Bayliss and Starling, 1899), little information about the behavior of the individual neurons that mediate these reflexes is available. Propulsive reflexes can be evoked by a number of different stimuli, for example, distension and mechanical or chemical stimulation of the mucosa (Furness and Costa, 1987). The dominant mechanical responses evoked by each stimulus are similar: contraction on the oral side of the stimulus and relaxation on the anal side. The neurons that mediate these reflexes must be contained within the gut wall because the reflexes can be evoked in the complete absence of any extrinsic input to the intestine. Despite this, there have been few studies of the electrophysiological behavior of individual neurons during the intestinal reflexes. The only substantial study using intracellular recording methods has been that of Hirst and his colleagues (Hirst and McKirdy, 1974; Hirst et al., 1975), who examined the behavior of neurons in the guinea-pig small intestine during reflexes evoked by distension. While that study identified neurons that might mediate the descending relaxation characteristic of such reflexes, it did not identify neurons that might be responsible for the ascending excitation recorded in contractility studies. Furthermore, it was not possible in that study to relate the electrophysiological properties of the neurons identified with other properties such as cell body shape, projections, or neurochemistry.

Distension is the most mechanically disruptive of the different stimuli known to evoke intestinal reflexes. Nevertheless, until recently, other forms of stimuli have not been successfully used, in vitro, to evoke such reflexes. The recent results of Smith and Furness (1988), however, have shown that mechanical stimulation of the mucosa can be used to evoke both ascending excitation and descending inhibition in the guinea-pig small intestine in vitro. Intracellular recordings can be made from the circular muscle within $2 \mathrm{~mm}$ of the point of stimulation using this method (Smith et al., 1990), thus facilitating analysis of the reflex pathways. The results of these and other studies indicate that the neural circuitry responsible for peristaltic reflexes lies almost entirely within the myenteric plexus. This present study was designed to identify myenteric neurons that respond to mechanical stimulation of the mucosa and to characterize the responses such stimuli evoked. 


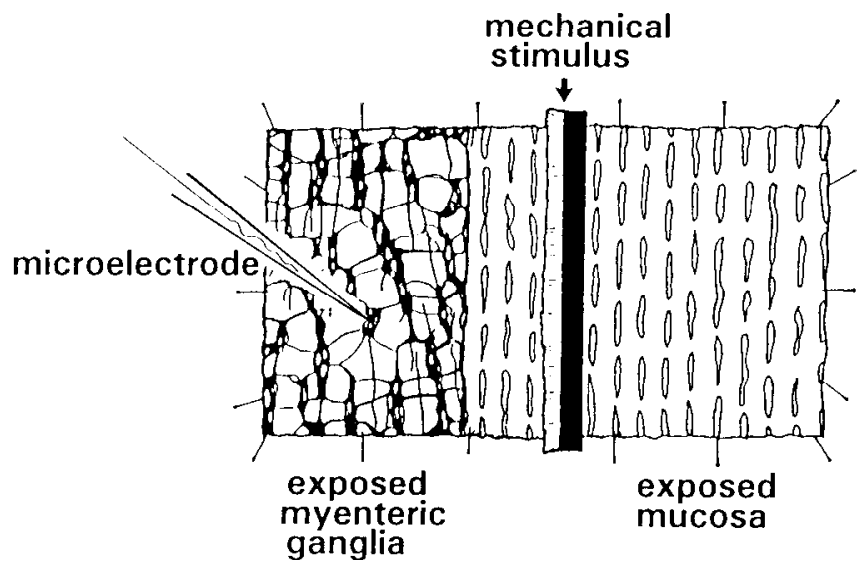

Figure 1. Schematic drawing of the experimental preparation. A segment of guinea-pig small intestine was opened along its mesenteric border and pinned serosal surface down in an organ bath. The mucosa, submucosa, and circular muscle were dissected from the myenteric plexus at either the oral or the anal end of the segment. Neurons were impaled in the cleared myenteric plexus. The preparation was stimulated by stroking the exposed mucosa of the intact end with a mechanically driven brush. Note that the drawing is not to scale; the recording site was usually 4-12 $\mathrm{mm}$ from the point at which the brush first touched the mucosa, and the brush was moved away from the recording site during a stimulus.

\section{Materials and Methods}

Male or female guinea pigs weighing $250-450 \mathrm{gm}$ were killed by being stunned and then having their carotid arteries and spinal cords cut. A $2-4-\mathrm{cm}$ segment of small intestine lying at least $10 \mathrm{~cm}$ oral to the ileocaecal junction was then removed and placed in physiological saline (see below). The oral end of the segment was identified so that the orientation of the preparation could be maintained. The segment was opened along its mesenteric border and pinned flat, mucosa uppermost, in a dissecting dish. The mucosa, submucosa, and circular muscle were dissected away from the underlying myenteric plexus at either the oral or the anal end of the opened segment, leaving the mucosa intact at the other end (Fig. 1). The preparation was then repinned with the serosal surface down in an organ bath that was mounted on the stage of an inverted microscope as described previously (Iyer et al., 1988). The section of intestine with intact mucosa was usually between 1 and 1.5 $\mathrm{cm}$ in length; the section of cleared myenteric plexus was usually about $1 \mathrm{~cm}$ in length. In a small number of cases, the mucosa was left intact at both ends of the preparation with an "island" of cleared myenteric plexus in the middle.

Throughout the dissection and the subsequent recording period, the preparation was bathed in a physiological saline (composition, in mM: $\mathrm{NaCl}, 120 ; \mathrm{KCl}, 5.0 ; \mathrm{CaCl}_{2}, 2.5 ; \mathrm{MgSO}_{4}, 1.0 ; \mathrm{NaH}_{2} \mathrm{PO}_{4}, 1.0 ; \mathrm{NaHCO}_{3}$, 25 ; glucose, 11.5 ; equilibrated with $95 \% \mathrm{O}_{2} / 5 \% \mathrm{CO}_{2}$ ); during the recording period, the preparation was maintained at $34^{\circ} \mathrm{C}$, but during the dissection, it was left at room temperature $\left(20-25^{\circ} \mathrm{C}\right)$. To minimize the

Table 1. Numbers of S- and AH-neurons that responded to mucosal stimulation

$\begin{array}{llllll}\begin{array}{l}\text { Cell } \\ \text { type }\end{array} & \begin{array}{l}\text { Position of } \\ \text { stimulus }\end{array} & \begin{array}{l}\text { Number } \\ \text { tested }\end{array} & \begin{array}{l}\text { Fast } \\ \text { EPSPs }\end{array} & \begin{array}{l}\text { Slow } \\ \text { responses }\end{array} & \begin{array}{l}\text { Total } \\ \text { re- } \\ \text { spond- } \\ \text { ing }\end{array} \\ \text { S } & \text { anal } & 71 & 27 & 0 & 27 \\ \text { S } & \text { oral } & 46 & 22 & 5 & 27 \\ \text { AH } & \text { anal } & 25 & 0 & 0 & 0 \\ \text { AH } & \text { oral } & 28 & 0 & 2 & 2\end{array}$

Nine S-neurons and $3 \mathrm{AH}-n$ eurons that were tested for responses from both sides are included in each sample. possibility of contractions disturbing the recording electrode, hyoscine $(1 \mu \mathrm{M})$ and nicardipine $(3 \mu \mathrm{M})$ were added to the bathing solution.

Recordings were made from myenteric neurons in the cleared region of the preparation using conventional intracellular recording methods (Bornstein et al., 1984; Jyer et al., 1988). The microelectrodes used in these experiments were filled either with $0.5 \%$ Lucifer yellow in $0.5 \mathrm{M}$ $\mathrm{KCl}$ solution (Bornstein et al., 1984) or with $4 \%$ biocytin ( $\mathrm{Ne}$-biotinylL-lysine; Sigma; Horikawa and Armstrong, 1988) in $2 \mathrm{M} \mathrm{KCl}$ containing $0.05 \mathrm{~m}$ Tris buffer $(\mathrm{pH}, 7.4)$. The resistances of the former group of electrodes were in the range of $150-280 \mathrm{M} \Omega$, while the latter group had resistances in the range of 80-180 M $\Omega$. Each type of electrode was used to inject a marker dye by the passage of hyperpolarizing current $(0.4-$ $0.8 \mathrm{nA}$ for 3-10 $\mathrm{min}$ ) into the impaled neurons during and after the recording period.

The preparation was stimulated in 2 ways. An etched tungsten stimulating electrode (tip diameter, $20 \mu \mathrm{m}$ ) was used to stimulate internodal strands focally to aid in characterizing impaled neurons. This electrode was normally placed on a circumferentially directed internodal strand connected with the ganglion being studied and was usually positioned at least $150 \mu \mathrm{m}$ from any impaled neuron. The exposed mucosa was normally stimulated with a mechanical device that moved a brush, made from a cut duck feather, over the mucosa so that the villi were deformed (see Smith and Furness, 1988). The mechanical device was positioned so that the brush touched the surface of the mucosa close to the recording site and was moved longitudinally away from this site. Thus, the stimuli were from oral to anal when recordings were made on the oral side of the brush and from anal to oral when the recordings were made on the anal side of the stimulated region. When the mucosa was left intact at both ends of the preparation, the mechanical stroker could not be used to stimulate each end during an impalement, and a hand-held artist's brush was used to stimulate one end of the preparation. Care was taken to avoid damage to the mucosa during stimulation, and experiments were terminated whenever visible damage occurred.

Once a neuron had been impaled, it was classified as either an $\mathrm{AH}$ neuron or an S-neuron using the criteria originally defined by Hirst et al. (1974). The action potentials in AH-neurons are followed by a prolonged afterhyperpolarization lasting at least $4 \mathrm{sec}$; S-neurons lack such hyperpolarizations. Focal stimulation evokes prominent fast excitatory synaptic potentials in S-neurons, but rarely evokes such responses in AH-neurons.

After a neuron had been characterized electrophysiologically, its responses to mucosal stimulation had been determined, and it had been injected with dye, the ganglion and the position of the electrode were drawn (Iyer et al., 1988). Further impalements in such a preparation were always made in a different ganglion so that it was not possible to confuse one injected neuron with another following the histochemical processing.

At the end of each experiment, the preparation was repinned in a dissecting dish and fixed overnight at $4{ }^{\circ} \mathrm{C}$ in $2 \%$ formaldehyde plus $15 \%$ of a saturated solution of picric acid. The preparation was cleared in 3 changes of dimethyl sulfoxide and 3 changes of PBS, and then the anal end was marked, and the preparation was unpinned. Preparations containing neurons injected with Lucifer yellow were mounted in buffered glycerol and viewed under a fluorescence microscope so that their shapes could be determined. Preparations containing neurons injected with biocytin were reacted with avidin coupled to horseradish peroxidase and then carried through a diaminobenzidine reaction (Furness et al. $1988 \mathrm{~b}$ ). These preparations were then mounted in Depex and examined under white light using phase-contrast objectives. Biocytin-injected neurons were drawn using a camera lucida.

\section{Results}

Forty-eight AH-neurons and $108 \mathrm{~S}$-neurons were characterized electrophysiologically and tested to see if they responded electrically to mechanical stimulation of the mucosa. The electrophysiological properties of these neurons were very similar to those previously reported for these 2 classes of myenteric neurons (see Table I of Iyer et al., 1988). In this present study, the action potentials of the AH-neurons were $84 \pm 8 \mathrm{mV}$ (mean \pm $\mathrm{SD}$ ) in amplitude and $2.5 \pm 0.4 \mathrm{msec}$ in half-width, and those of the S-neurons were $68 \pm 12 \mathrm{mV}$ and $1.4 \pm 0.2 \mathrm{msec}$. The mean input resistance of the AH-neurons was $230 \pm 100 \mathrm{M} \Omega$. 


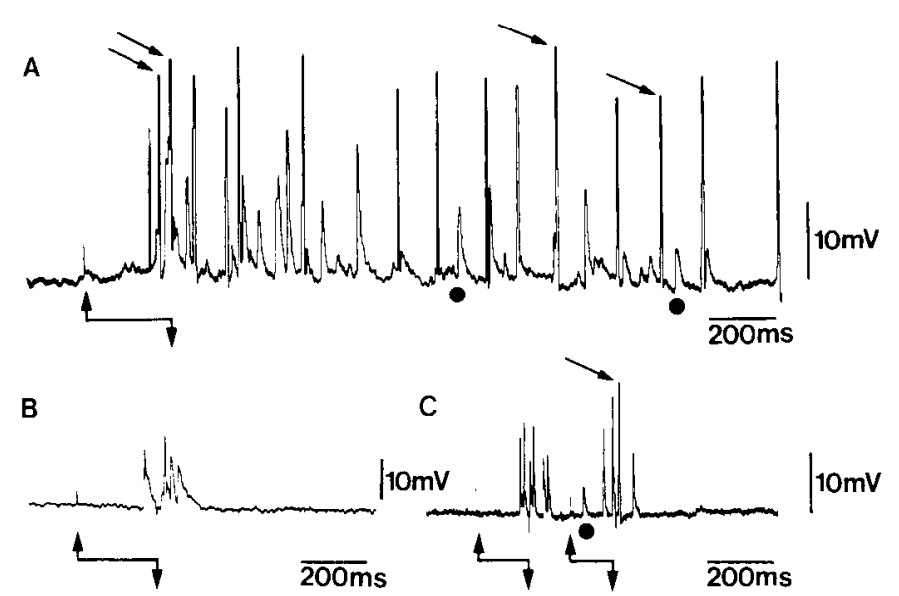

D

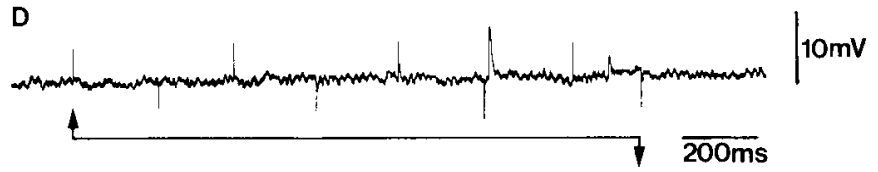

Figure 2. Examples of fast EPSPs and action potentials evoked in 4 $\mathrm{S}$-neurons by stroking of mucosa. The responses illustrated in $A, C$, and $D$ were obtained by stimulating the mucosa oral to the impaled neurons; that in $B$ was obtained by stroking the mucosa anal to the neuron. Stimuli were applied and withdrawn at the arrows; the sharp deflections in the records at the onset and end of each stroke are artifacts produced by the relay controlling the mechanical stroking device. Four strokes were applied to the mucosa between the arrows in $D$. Action potentials (examples are indicated by arrows) evoked in the neurons of $A$ and $C$ were truncated by the frequency response of the chart recorder used to record them. In $A$ and $C$, the dots show examples of fast EPSPs that did not evoke action potentials.

while that of the S-neurons was $335 \pm 190 \mathrm{M} \Omega$. There were no detectable differences in any of these parameters between neurons impaled with Lucifer yellow-filled electrodes and those impaled with biocytin-filled electrodes. Fast EPSPs were recorded only in the S-neurons. Neurons of both classes exhibited slow EPSPs in response to focal electrical stimulation (1-10 pulses at $10 \mathrm{~Hz}$ ) of circumferentially directed internodal strands connecting with the ganglia containing the impaled neurons.

\section{Responses to mechanical stimulation of the mucosa}

In all, $71 \mathrm{~S}$-neurons and $25 \mathrm{AH}$-neurons were tested for responses to stimulation of the mucosa on the anal side, and 46 S-neurons and $26 \mathrm{AH}$-neurons were tested for responses to mucosal stimulation on the oral side. (Some neurons were tested for responses from both sides.) Table 1 summarizes the results obtained. A significantly greater proportion of S-neurons responded to oral stimulation (59\%) than to anal stimulation (38\%; $\chi^{2}$ test $\mathrm{df}=1 ; p<0.05$ ). Neurons that responded to stimulation from the oral side were taken to be in descending reflex pathways, and those that responded to stimuli from the anal side were taken to be in ascending pathways.

Types of responses. Stroking the mucosa evoked fast EPSPs in many of the S-neurons studied (e.g., Figs. 2, 11, 13). These responses could be observed throughout impalements lasting up to $90 \mathrm{~min}$. Similar responses were observed in neurons impaled within $2 \mathrm{hr}$ of beginning a dissection and in neurons impaled after $8 \mathrm{hr}$, as long as the mucosa at the stimulation site remained intact. The patterns of response in these neurons var-

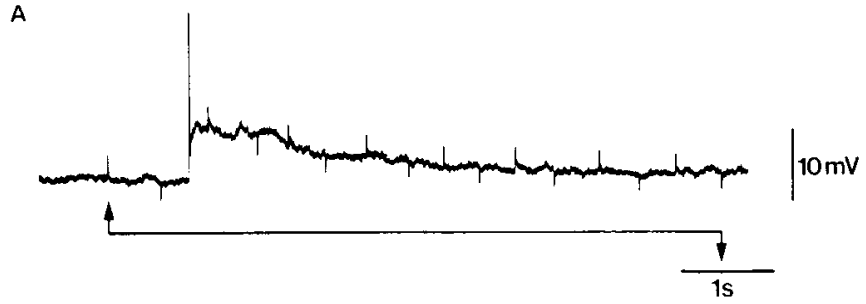

B

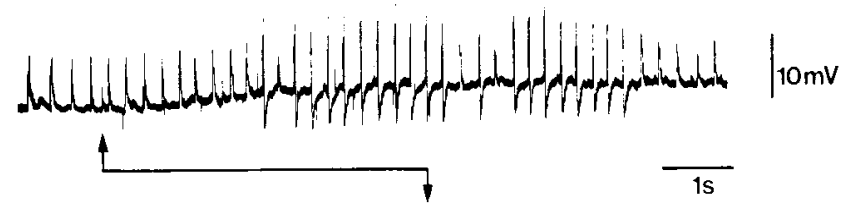

Figure 3. Slow depolarizations evoked in $2 \mathrm{~S}$-neurons by stimulation of mucosa on oral side. $A$. The response in this neuron was an action potential evoked by the first stimulus and a slow depolarization that declined during the later stimuli in the train. $B$, Repeated stimulation of the mucosa depolarized this neuron so that depolarizing current pulses passed through the recording electrode (upward deflections) that had been subthreshold for the generation of action potentials exceeded threshold. Each action potential was followed by a prominent hyperpolarization. The increased excitability persisted for several seconds after the stimulation ended.

ied from a prolonged burst of fast EPSPs lasting several seconds after a single stroke (Fig. $2 A$ ) to a response pattern in which fast EPSPs were only observed occasionally during repeated strokes (Fig. 2D). The usual response, however, was a burst of fast EPSPs that began during the stimulus and continued for less than 0.5 sec after the stimulus (Fig. $2 B, C$ ).

$\Lambda$ small proportion of the $S$-neurons $(5$ cells) responded to the mucosal stimulus with a substantial depolarization that lasted 6-20 sec and was sometimes preceded by an action potential (Fig. 3). This slower depolarization was not clearly associated with any change in the input resistance of the neuron as measured by passage of hyperpolarizing current pulses through the microelectrode. It was, however, responsible for an increase in the excitability of the neuron (Fig. 3B). Responses of this type were only observed in neurons lying on the anal side of the stimulus. In 3 of the cells, these responses could only be evoked when trains of stimuli were repeated less frequently than about 1 per $5 \mathrm{~min}$.

Only 2 of the $48 \mathrm{AH}$-neurons studied showed a discernible response to mucosal stimulation (Fig. 4). In both of these neurons, stroking the mucosa evoked a slow depolarization that was sometimes preceded by a burst of 1 or more action potentials, a response similar to that seen in some S-neurons (Fig. $3 A$ ). Like the slow depolarizations seen in S-neurons, the slow depolarizations in AH-neurons could not be evoked more frequently than about every $5 \mathrm{~min}$. Both responding AH-neurons were located on the anal side of the stimulus.

Whether the slow depolarizations seen in S-neurons and $\mathrm{AH}$ neurons were due to synaptic activity or to movement of the preparation in response to the mechanical stimulus could not be determined.

Patterns of responses to mucosal stroking. The responses evoked by mucosal stimulation varied widely in time course and in the amplitude of the fast EPSPs evoked (Fig. 2). The response evoked by a stimulus can be characterized by 4 partially related components: the amplitudes of the fast EPSPs evoked, the number 


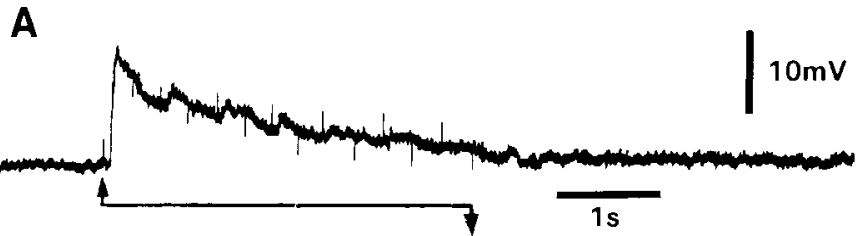

B
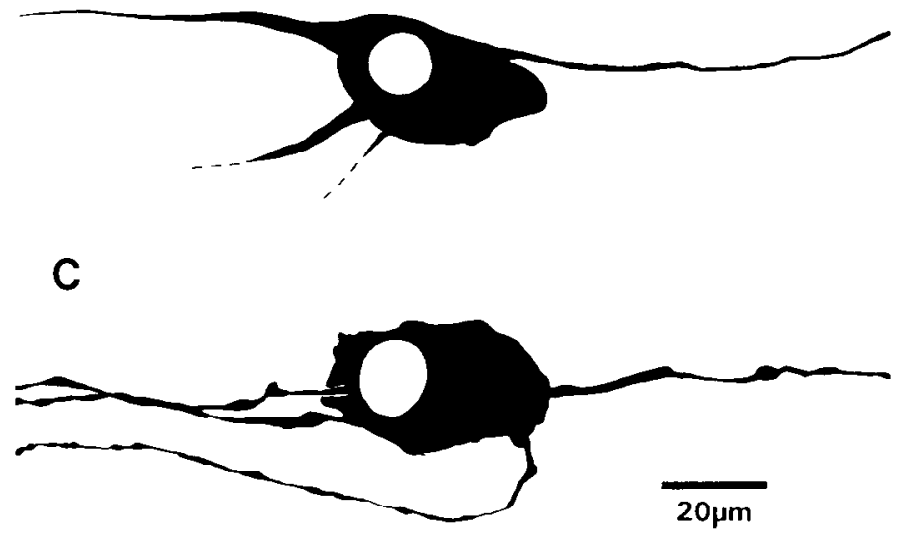

Figure 4. Shapes of AH-neurons injected with biocytin and example of response to mucosal stroking in one of them. $A$, A slow response evoked in an AH/Dogiel type II neuron (see Results for definition of Dogiel type II neurons) by stimulation of the mucosa on the oral side. $B$, A camera lucida drawing of this AH/Dogiel type II neuron, which had been injected with biocytin. $C$, A camera lucida drawing of another biocytin-injected $\mathrm{AH} /$ Dogiel type II neuron that did not respond to mucosal stimulation. Note that the shapes of the responding and nonresponding neurons are similar.

of fast EPSPs evoked, the duration of the burst of fast EPSPs, and the latencies of the individual fast EPSPs. Each of these has a significant effect on the excitability of neurons involved in the reflex.

The fast EPSPs evoked during a stimulus often occurred at high frequencies. For example, individual stimuli evoked bursts of fast EPSPs lasting from 14.7 to $27.3 \mathrm{sec}$ in the neuron illustrated in Figure $2 A$, the average frequency within these bursts ranged from 3.5 to $6.3 \mathrm{~Hz}$, and the frequency within the first $0.5 \mathrm{sec}$ of the response was approximately $35 \mathrm{~Hz}$. The fast EPSPs in this neuron sometimes evoked action potentials separated by intervals as short as 10-20 msec (giving a maximum frequency of $50-100 \mathrm{~Hz}$; see below). In most neurons of either the ascending or the descending pathway, the trains of fast EPSPs were considerably briefer, lasting $0.3-1 \mathrm{sec}$. The mean frequencies of fast EPSPs within these responses ranged from less than 1 per stimulus (e.g., Fig. $2 D$ ) up to $35 \mathrm{~Hz}$ for single neurons, with considerably higher frequencies also being observed within a response.

The delay between the beginning of a stimulus and the first fast EPSP in a response ranged in different neurons from 80 to $300 \mathrm{msec}$, with most neurons showing responses within 200 $250 \mathrm{msec}$ of the brush touching the surface of the mucosa (see below). All the neurons impaled in this study were located between 5 and $12 \mathrm{~mm}$ from the nearer end of the stimulated region of mucosa. This indicates that both the ascending and the descending reflex pathways transmit information slowly, with speeds in the order of $0.05 \mathrm{~m} / \mathrm{sec}$.

The latencies of the slow responses evoked in some neurons
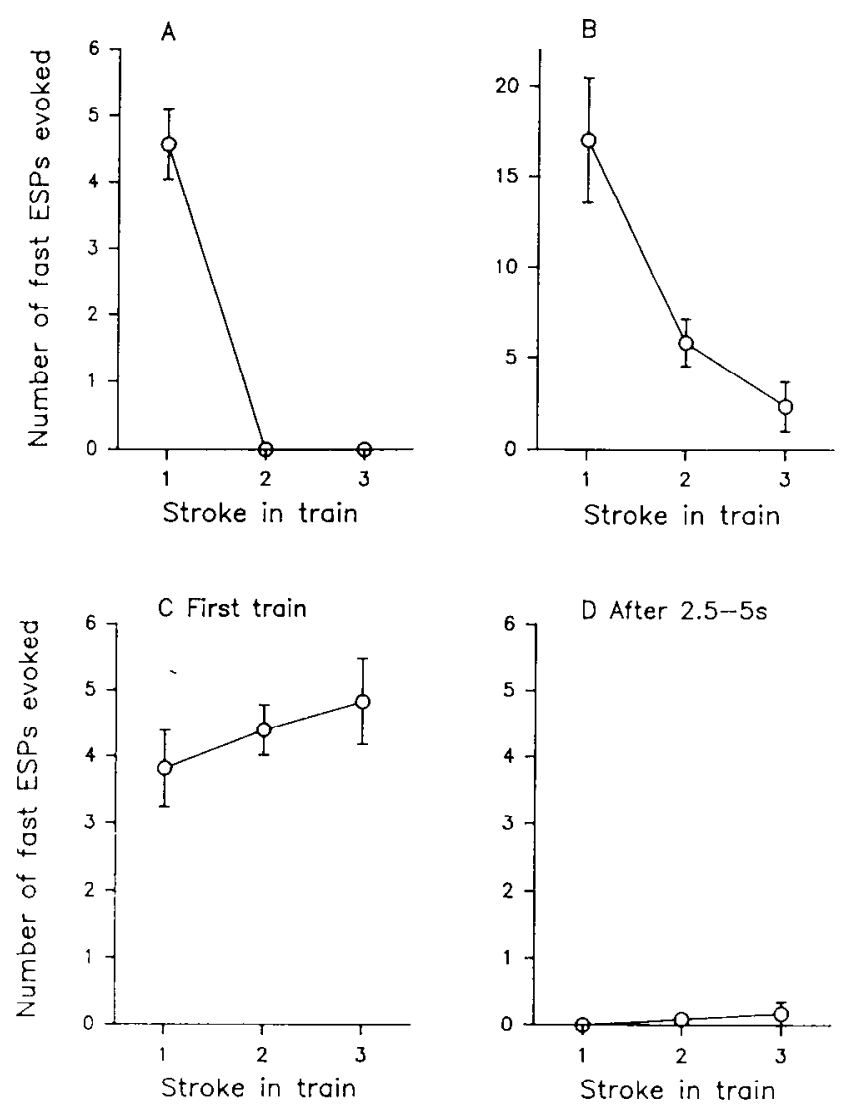

Figure 5. Examples of decline in number of fast EPSPs evoked in 3 different neurons by successive stimuli lasting $280 \mathrm{msec}$ and separated by $280 \mathrm{msec}$ in trains of stimuli delivered to mucosa on anal side. Each point represents the mean \pm SE of at least 5 trials repeated 20-300 sec apart. In the neurons shown in $A$ and $B$, the number of fast EPSPs evoked by a stroke declined rapidly. In contrast, the responses in the neuron shown in $C$ were slightly enhanced by successive stimuli, but disappeared when the train was repeated $2.5-5 \mathrm{sec}$ after the first train of stimuli $(D)$.

by activation of a descending pathway were of a similar order to those of the fast EPSPs, ranging from 200 to $420 \mathrm{msec}$.

The mean number of fast EPSPs evoked by a stimulus remained constant when the stimuli were repeated $20 \mathrm{sec}$ to 5 min apart (10 neurons, each with up to 35 trials). However, when stimuli separated by $0.25-0.5 \mathrm{sec}$ were delivered in trains at intervals of $20 \mathrm{sec}$ to $5 \mathrm{~min}$, the responses to later stimuli in each train were markedly attenuated. This effect was especially prominent for the bursts of fast EPSPs produced in the ascending reflex pathways (e.g., Fig. 5). In most cases, the first stimulus in a train evoked several fast EPSPs, but subsequent stimuli evoked fewer synaptic potentials (Fig. $5 A, B$ ). In one neuron, the mean number of fast EPSPs evoked by each stimulus in an initial train increased slightly as the train proceeded, but the response to a similar train delivered $2.5-5 \mathrm{sec}$ later was profoundly depressed (Fig. 5C,D).

A similar, but less marked, effect was observed in the descending pathways (Fig. 6). In 4 out of 6 neurons analyzed in detail in these pathways, the number of fast EPSPs evoked by each stimulus in a train of up to 20 stimuli declined markedly during the first 3-5 stimuli and was then maintained throughout the period of stimulation. In the other 2 neurons, the initial response was very small, and some enhancement of the number 

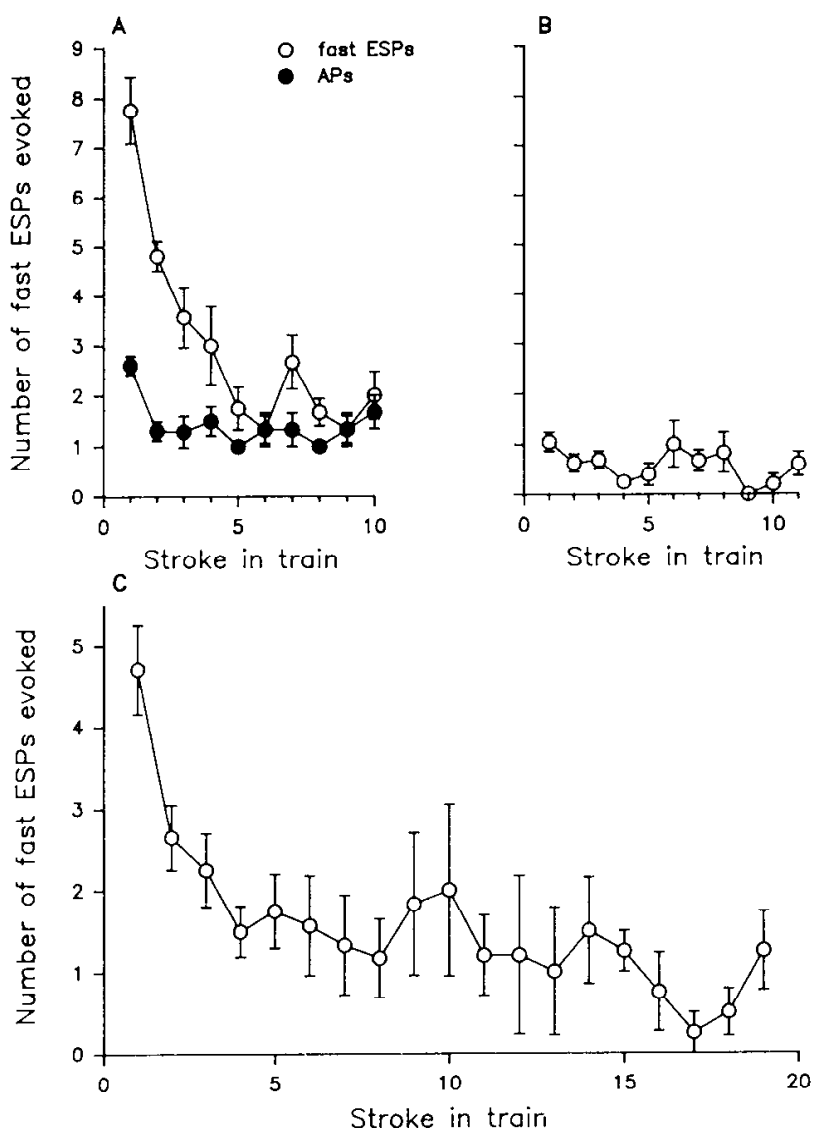

Figure 6. Effects of repetitive stimulation of mucosa (parameters were similar to those in Fig. 5) oral to 3 S-neurons on number of fast EPSPs evoked by individual stimuli in each train. Each point is the mean \pm SE of at least 5 trials. Mucosal stimulation evoked both fast EPSPs (open circles) and action potentials (solid circles) in the cell shown in $A$.

of fast EPSPs that could be evoked was observed during the first few stimuli before a plateau was reached.

The amplitudes of the fast EPSPs evoked by mucosal stimulation often varied widely within the one neuron, with fast EPSPs as small as $1 \mathrm{mV}$ and as large as $25 \mathrm{mV}$ being recorded (Figs. 2, 7). A detailed analysis of these amplitudes was undertaken for 4 neurons in the descending reflex pathway and 2 neurons in the ascending pathway. The amplitude distributions were clearly not unimodal in 5 of these neurons, indicating that the stimuli cvoked fast EPSPs with 2 or more characteristic amplitudes. In the other neuron, the amplitudes of the fast EPSPs were distributed unimodally (not illustrated). The peaks of the multimodal distributions were not at integral multiples of the initial peak, indicating that these distributions were not due to quantal fluctuations in transmitter release from a single presynaptic fiber. This suggested that the variation in amplitudes was due to activation of several fibers, all impinging on the impaled neuron.

This hypothesis was supported by the observation that the decline in the number of fast EPSPs evoked by successive stimuli was accompanied by a change in the proportions of fast EPSPs in specific amplitude groups. This was most clearly seen in the neuron illustrated in Figures $6 A$ and $7 B$. For this neuron, the amplitude distribution is at least bimodal. However, many of the fast EPSPs evoked by the stimuli also evoked an action
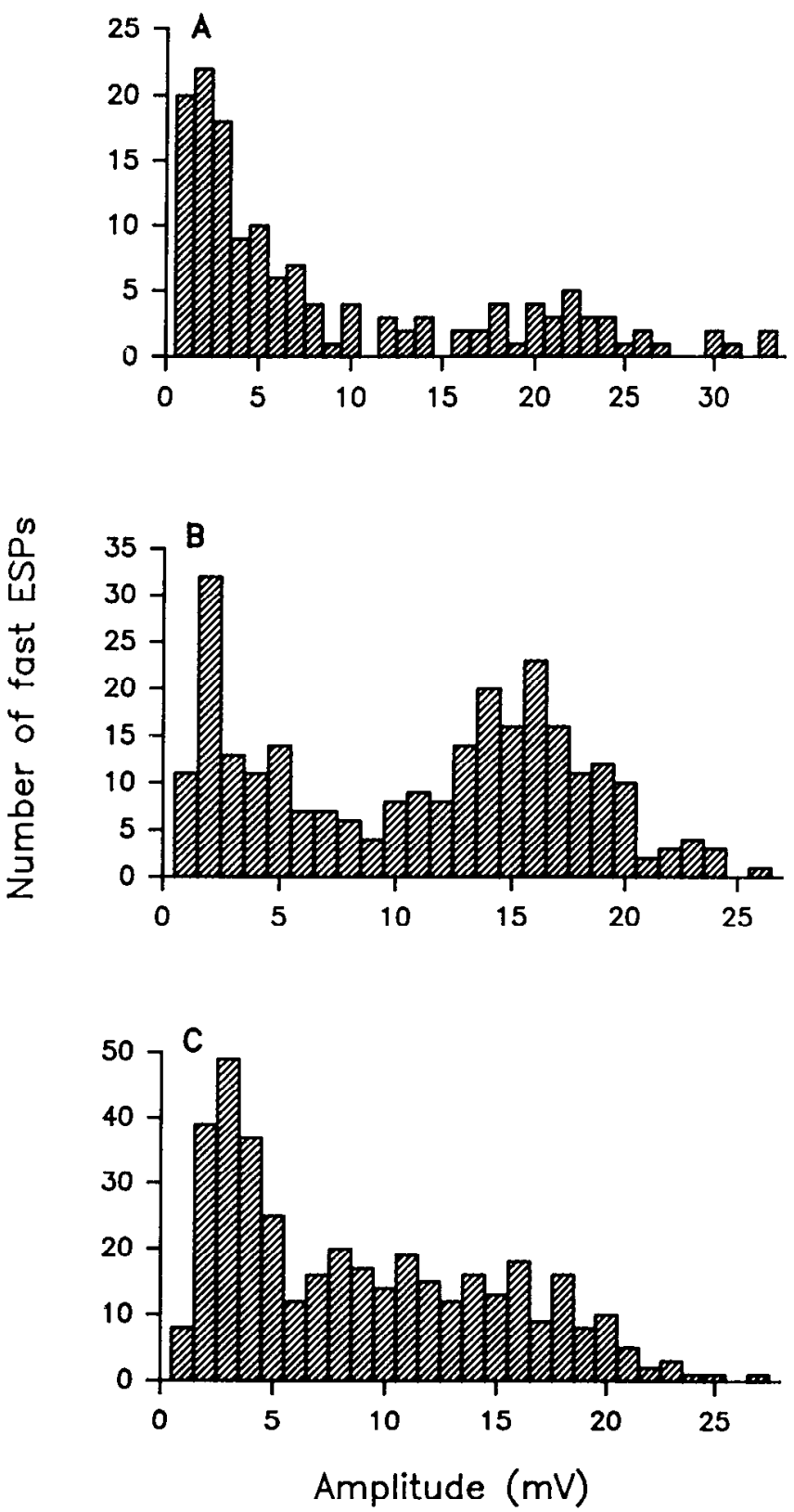

Figure 7. Amplitude distributions of fast EPSPs evoked by mucosal stimulation in neuron in ascending pathway $(A)$ and in neurons in descending reflex pathways $(B, C)$. In $B$ and $C$, many fast EPSPs triggered action potentials; the amplitudes of these fast EPSPs are not included in the distributions. All 3 amplitude distributions have at least 2 peaks.

potential (not included in Fig. $7 B$ ); these EPSPs can be treated as a separate group with amplitudes greater than $26 \mathrm{mV}$, the amplitude of the largest subthreshold fast EPSP recorded. Thus, at least 3 classes of fast EPSP were identified in this neuron, and, though the number of fast EPSPs evoked declined markedly with successive stimuli, the number of action potentials evoked declined less dramatically (Fig. $6 A$ ). Later stimuli $(>5)$ in the trains evoked suprathreshold fast EPSPs almost exclusively, indicating that the stimulus no longer evoked action potentials in the input neurons producing the smaller subthreshold fast EPSPs. Similar changes in the amplitude distributions with successive stimuli were observed in each of the other 4 neurons examined.

The different-sized fast EPSPs also had different latencies in 


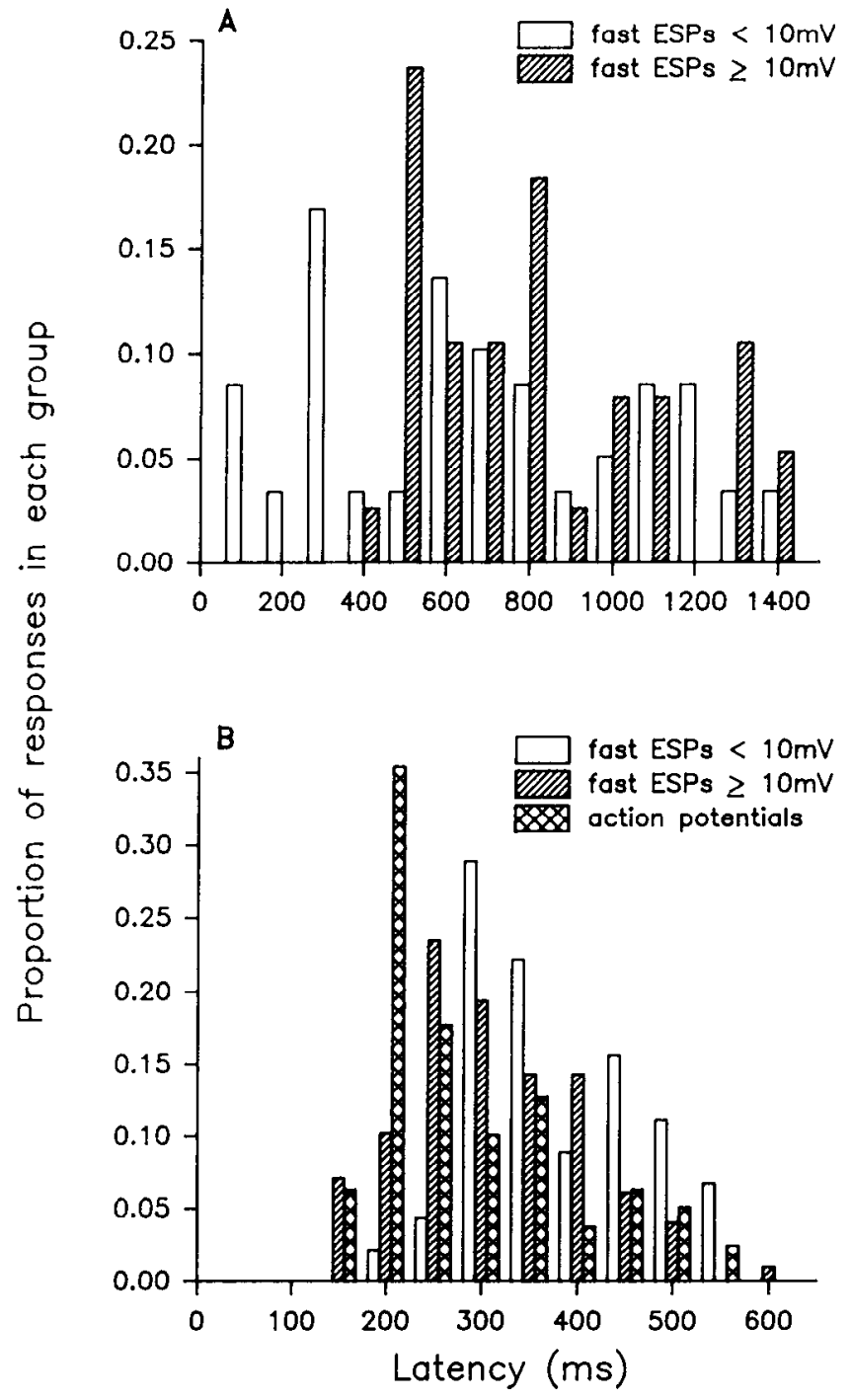

Figure 8. Comparison of latencies of fast EPSPs of different amplitudes evoked in neuron of Figure $7 A(A)$ and in neuron of Figure $7 B(B)$. The fast EPSPs in $A$ were divided into 2 groups on the basis of their amplitudes, with fast EPSPs $\geq 10 \mathrm{mV}$ being treated as one group and those $<10 \mathrm{mV}$ as another. In $B$, the responses were divided into 3 groups: $<10 \mathrm{mV}, \geq 10 \mathrm{mV}$ but subthrcshold, and suprathreshold. Each group of fast EPSPs had its own characteristic latency distribution, suggesting that they were due to firing of separate input neurons.

the 5 neurons examined (Fig. 8). For example, in the neuron illustrated in Figure $8 A$, small fast EPSPs were evoked within $100 \mathrm{msec}$ of the beginning of the stimulus, but larger fast EPSPs only occurred after a delay of $450 \mathrm{msec}$. In contrast, in the neuron shown in Figure $8 B$, large fast EPSPs were seen within $150 \mathrm{msec}$ of the stimulus and were most prominent within the next $150 \mathrm{msec}$; small fast EPSPs were only observed after 250 mscc and were most prominent $280-400 \mathrm{msec}$ after the start of the stimulus.

Mucosal stimulation evoked substantial numbers of action potentials in 2 of the neurons studied. In each, the minimum interval between action potentials was about $10 \mathrm{msec}$, indicating that an instantaneous firing frequency of about $100 \mathrm{~Hz}$ can be attained during a reflex (Fig. 9). The mean intervals were 95 and $270 \mathrm{msec}$, yielding average frequencies of firing during each response of 10.5 and $3.7 \mathrm{~Hz}$. While the latter value is quite low,

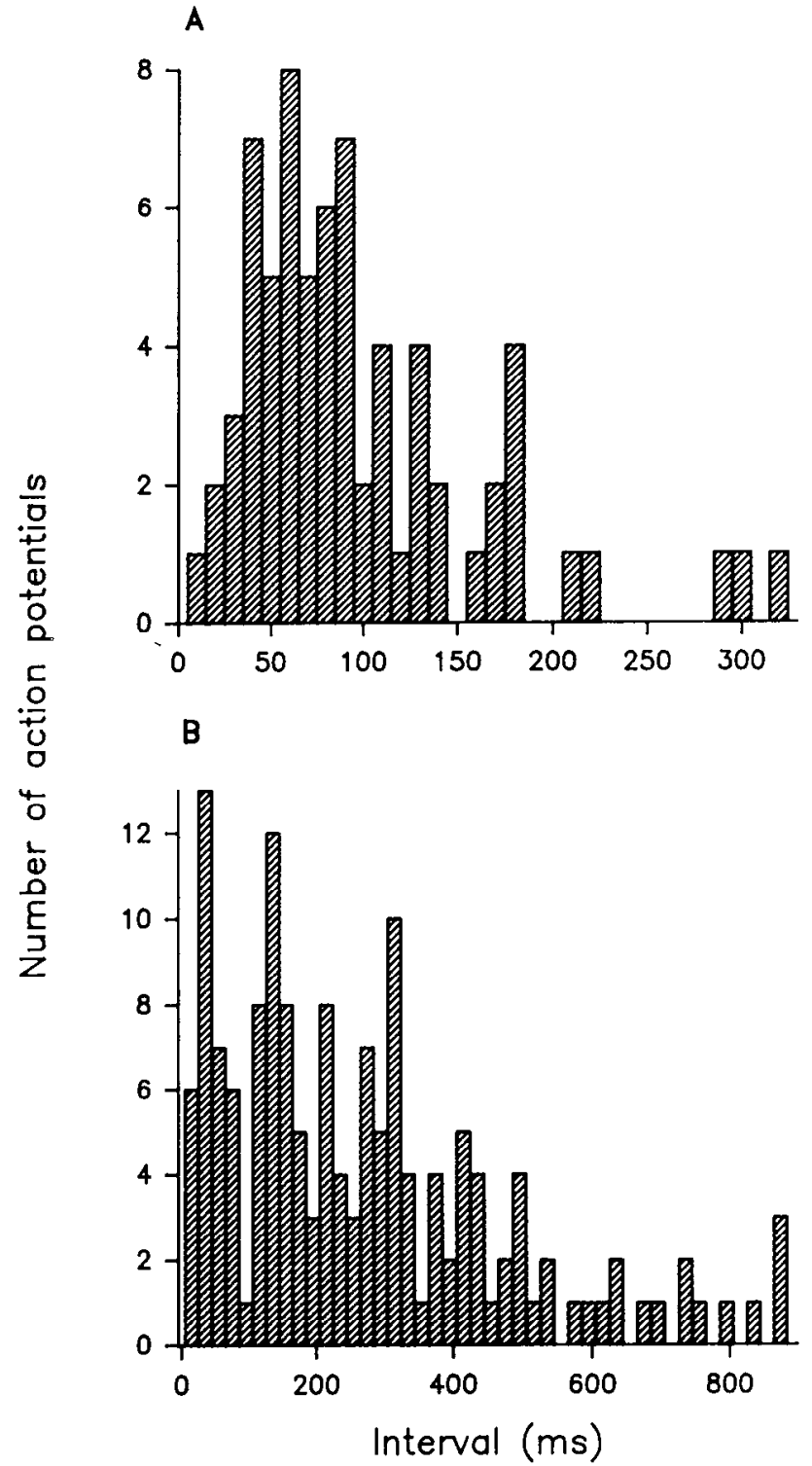

Figure 9. Distributions of intervals between successive action potentials within responses evoked by mucosal stimulation in S-neurons illustrated in Figure $7, B$ and $C$. In $A$, the modal interval is about 60 msec, which corresponds to a frequency of $17 \mathrm{~Hz}$.

the interval distribution for this neuron was clearly multimodal, and about $20 \%$ of the intervals were in the first peak, which had a mean of $46 \mathrm{msec}$, equivalent to a frequency of $22 \mathrm{~Hz}$.

\section{Morphological types of neurons that respond to mucosal stimulation}

Neurons in the myenteric plexus have a number of characteristic shapes (Dogiel, 1899; Furness et al., 1988b; Stach, 1989; Furness and Bornstein, 1991), and these have been correlated with their neurochemistry and basic electrophysiological properties (Hodgkiss and Lees, 1983; Bornstein et al., 1984; Erde et al. 1985; Katayama et al., 1986; Iyer et al., 1988). Four distinct morphological classes of neurons have been identified by injection of the dye Lucifer yellow into myenteric neurons of the guinea-pig small intestine, though a significant number of neurons had shapes that were not readily classified (Furness et al., 


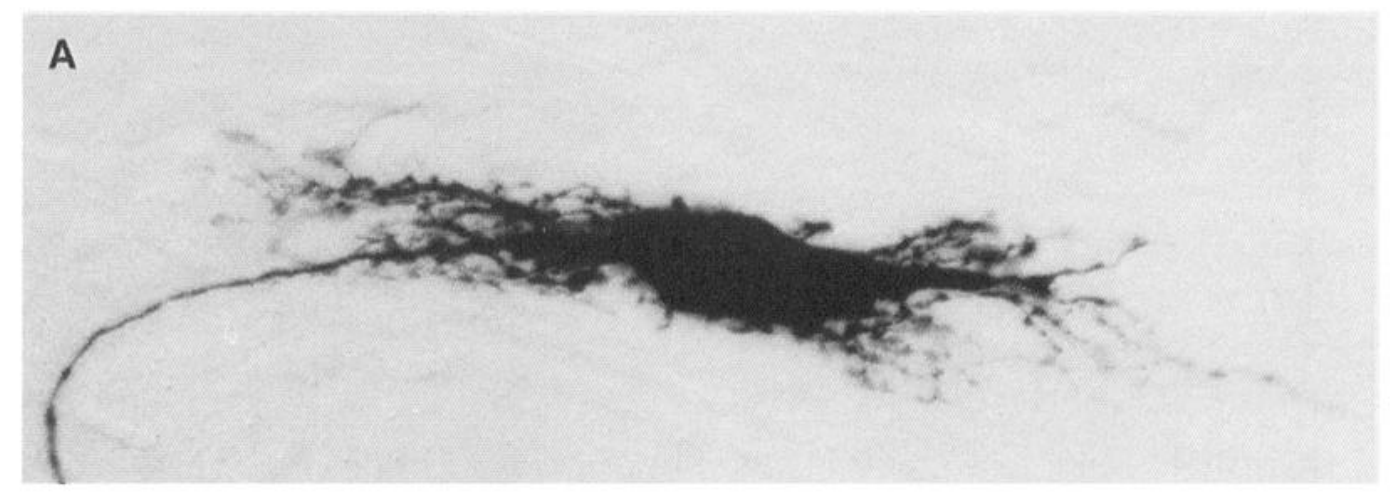

B

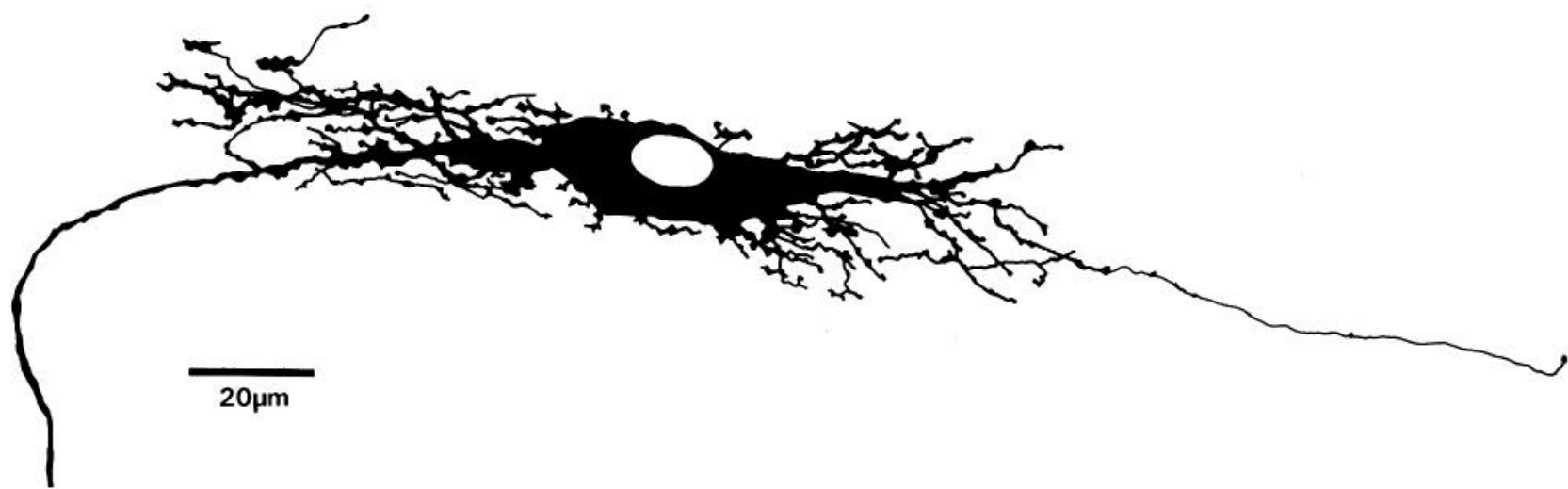

Figure 10. Filamentous S-neuron that had been injected with biocytin. $A$ shows a photomicrograph and $B$ shows a camera lucida drawing of the same uniaxonal neuron, which projected anally and responded to activation of a descending pathway. The long process shown to the right of the cell body in $B$ terminates at the point shown, while the process shown to the left continued for more than 2 mm anally. Biocytin appears to fill the neuron completely and reveals finer details of the neuronal morphology than do other intracellular dyes that have been used to mark myenteric neurons.

1988b). The classifiable neurons were Dogiel type I neurons, which typically have a single long process and several short lamellar processes; Dogiel type II neurons with large smooth cell bodies, several long processes, and few short processes; filamentous neurons with a single long process and many fine short processes; and small, simple neurons with small cell bodies, a single long process, and few short processes. These 4 classes of neurons could be identified among the 99 neurons whose shapes were characterized by injection of Lucifer yellow or biocytin in the present study.

The 28 AH-neurons examined were all Dogiel type II neurons (e.g., Fig. 4), confirming previous studies (Bornstein et al., 1984; Katayama et al., 1986; Iyer et al., 1988); none of the 71 $\mathrm{S}$-neurons identified had this shape. The S-neurons were nearly all uniaxonal: 44 were Dogiel type I neurons; the other 27 were small simple neurons, filamentous neurons, or unclassifiable. Some neurons of all the morphological classes of S-neurons responded to mucosal stimulation (Table 2). Because the numbers of filamentous and small neurons identified were small, they were pooled for comparison with the Dogiel type I neurons. Significantly fewer Dogiel type I neurons responded to mucosal stimulation than did the other classes of S-neurons ( $\chi^{2}$ test; $p$ $\ll 0.001)$. About half the Dogiel type I neurons tested were in descending pathways. However, almost all the neurons with other shapes (e.g., Figs. 10, 11) responded to oral stimuli. Furthermore, the great majority of neurons in the ascending path- way were either small or filamentous (e.g., Fig. 11), whereas only $13 \%$ of the Dogiel type I neurons tested responded to anally placed stimuli.

The neurons illustrated in Figures 4, 10, and 11 were injected with biocytin and processed to produce an opaque reaction product (see Materials and Methods). This revealed far more of the extent of the long processes of injected neurons than did Lucifer yellow. The axons of biocytin-injected neurons were often traced for more than $4 \mathrm{~mm}$ within the myenteric plexus, while the longest distance we have traced axons of myenteric neurons injected with Lucifer yellow is about $600 \mu \mathrm{m}$ (Furness et al., 1988b).

\begin{tabular}{|c|c|c|c|c|}
\hline $\begin{array}{l}\text { Cell } \\
\text { type }\end{array}$ & Pathway & Response & $\begin{array}{l}\text { Dogiel } \\
\text { type I }\end{array}$ & Other \\
\hline \multirow[t]{2}{*}{$\mathrm{S}$} & descending & yes & 9 & 10 \\
\hline & & no & 11 & 1 \\
\hline \multirow[t]{2}{*}{$S$} & ascending & yes & 3 & 12 \\
\hline & & no & 21 & 4 \\
\hline
\end{tabular}

Categories of shape include Dogiel type I and "other" (incorporating those neurons characterized as filamentous or small; AH-neurons were all Dogiel type II). 


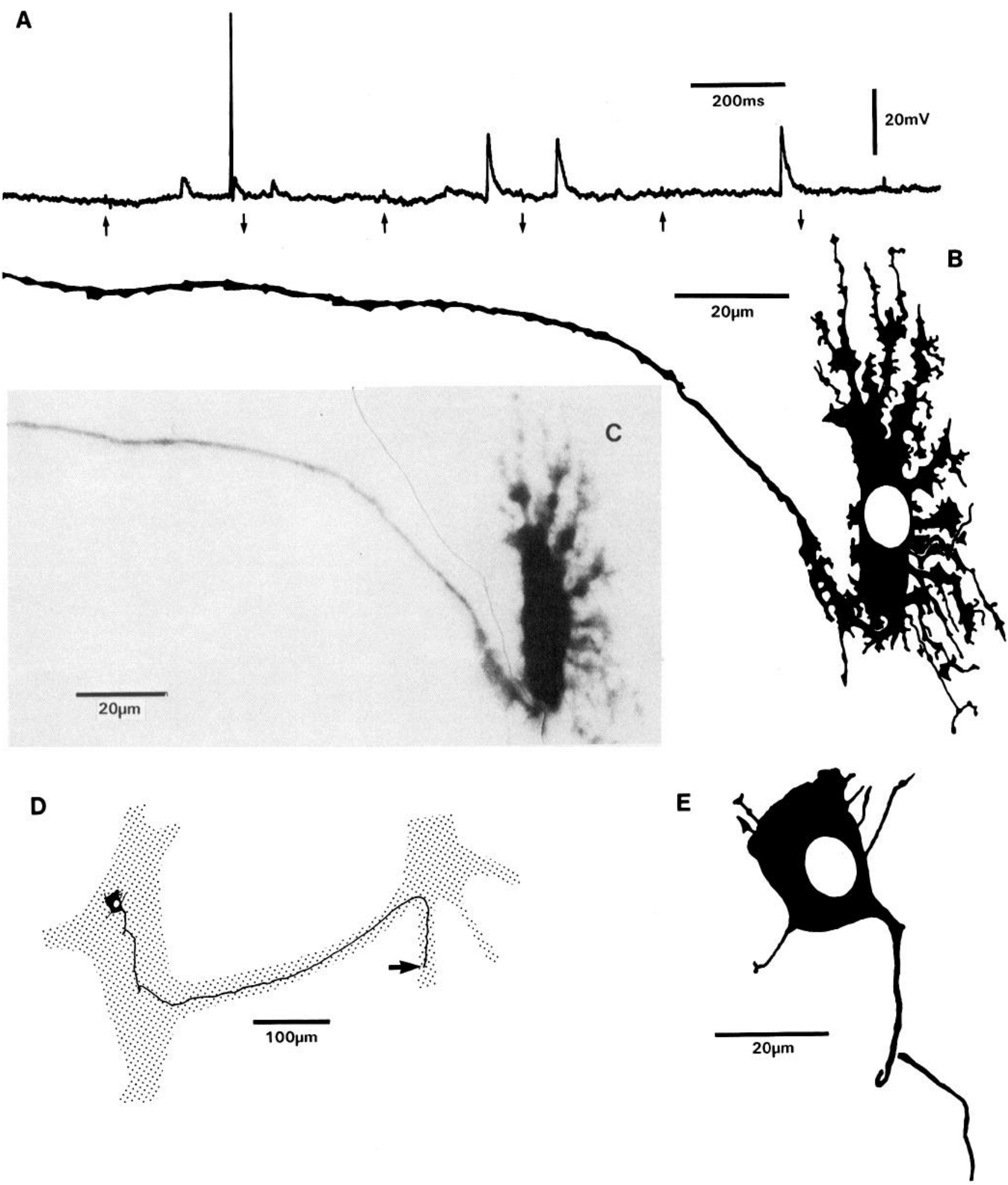

Figure 11. Two neurons in ascending pathway. $A$ shows an intracellularly recorded response of the neuron in $B$ and $C$ to a train of 3 stimuli applied to the mucosa anal to the recording site; the arrows show the times at which the individual strokes began and ended. $B$ and $C$ show a micrograph and a camera lucida drawing of this neuron, which had been injected with biocytin. This neuron had Dogiel type I morphology and a single axon that projected orally for more than $3 \mathrm{~mm}$ and had 2 small side branches in other myenteric ganglia. $D$ shows a low-power camera lucida drawing of the neuron whose response to mucosal stimulation is shown in Figure $2 B$; the full extent of this neuron in the myenteric plexus (stippled region) is shown. The axon ended abruptly at a small expansion bulb (arrow). $E$ shows a drawing of the cell body of this neuron, a small simple neuron, to the same scale as that shown in $B$. 
The projections of 34 S-neurons that had been injected with biocytin were traced. Of these, 15 received input from a descending pathway and 6 from an ascending pathway. The other 13 neurons did not respond to mucosal stimulation, 4 from oral (descending pathway), 5 from anal (ascending pathway), and 4 from either side.

The S-neurons were divided into 4 groups on the basis of their projections. Five $S$-neurons projected along the intestine, with side branches that ramified within some of the ganglia that their axons traversed. An example of such a neuron is illustrated in Figure 12. These neurons were traced for between 2.7 and $5.8 \mathrm{~mm}$ along the intestine before the biocytin reaction product became too faint to be detected, but only projected $0.1-0.7 \mathrm{~mm}$ around the intestinal circumference. Four of these neurons were filamentous, and the other was a Dogiel type I neuron. Three were in the ascending reflex pathway and projected orally. The other 2 were in the descending pathway and had anal projections. These neurons are probably interneurons.

A second group of $3 \mathrm{~S}$-neurons had a dramatically different projection pattern (Fig. 13). The axons of these neurons branched close to their cell bodies and then ramified extensively in the tertiary plexus within $2-2.5 \mathrm{~mm}$ of their cell bodies. Two of these neurons were in the descending pathway; the other did not respond to stimulation of the ascending pathway and was not tested for responses from the oral side. The cell bodies of these 3 neurons were difficult to classify by shape, and they were included in the non-Dogiel type I class of neurons. Ultrastructural studies indicate that, in the guinea-pig small intestine, the motor innervation of the longitudinal muscle appears to lie entirely within the tertiary plexus (Furness et al., 1988a; I. J. Llewellyn-Smith, M. Costa, and J. B. Furness, unpublished observations); thus, these 3 neurons are probably motor neurons to the longitudinal muscle.

Seven S-neurons had short $(<400 \mu \mathrm{m})$ projections along the length of the intestine before they ended in 1 or more (up to 3 ) swellings similar to the expansion bulbs described by Erde et al. (1985). An example of one of these neurons is illustrated in Figure 11, $C$ and $D$. Expansion bulbs appear where the axon of a neuron has been damaged or broken during the dissection, and each represents the site of accumulation of material being transported along the axon. In this preparation, axons with expansion bulbs may be presumed to have entered the circular muscle before it was removed, either to terminate within this layer or to continue on to the submucosa or mucosa. It is also possible that some of the axons that run within the myenteric plexus were damaged during the dissection. Thus, it seems likely that neurons of this group were either short motor neurons supplying the circular muscle or possibly interneurons supplying the submucosa. All were either small cells or filamentous cells. Four neurons of this class were in a descending pathway, 2 were in an ascending pathway, and 1 could not be excited by stimulation of the mucosa on the oral side.

The final major class of neurons whose projections could be identified consisted predominantly of Dogiel type I neurons (16 of 17 neurons) that projected more than $1 \mathrm{~mm}$ along the intestine before ending in an expansion bulb or becoming too faint to detect. Thirteen of these neurons projected anally for between 1.0 and $4.4 \mathrm{~mm}$ (mean, $3.1 \pm 1.3 \mathrm{~mm}$ ) and circumferentially for between 0.1 and $1.7 \mathrm{~mm}$ (mean, $0.6 \pm 0.5 \mathrm{~mm}$ ). The other 4 projected orally for $1.7-5.9 \mathrm{~mm}$ (mean, $3.6 \pm 1.7 \mathrm{~mm}$ ) and circumferentially for $0.5-1.1 \mathrm{~mm}$ (mean, $0.7 \pm 0.3 \mathrm{~mm}$ ). Most (11) did not respond to mucosal stimulation; indecd, 4 showed no response to either oral or anal stimuli. Five neurons were in the descending pathway, though paradoxically, 3 of these projected orally. Only 1 of these long Dogiel type I neurons was in the ascending pathway, and it projected anally. While the functions of these neurons cannot be conclusively deduced from their projections, many ended in 1 or more expansion bulbs, and it seems likely that some project into the circular muscle and are circular muscle motor neurons.

The projections of 1 other S-neuron were identified in this study. This neuron, which was located in the descending pathway, was not classifiable according to the shape of its cell body and appeared to make many terminals in its own ganglion.

\section{Discussion}

This work is the first in which recordings have been made from myenteric neurons during mechanical stimulation of the mucosa. Both the electrophysiological characteristics and the morphology of neurons in ascending and descending pathways have been examined.

\section{Types of neurons identified in the reflex pathways}

Most of the neurons that responded to mucosal stimulation in this study were probably either interneurons or motor neurons in the reflex pathways. Action potentials evoked in the sensory processes of the sensory neurons by mucosal stimulation would be expected to invade the cell bodies of these neurons antidromically without any associated synaptic potential. However, all the action potentials observed were associated with either fast

\footnotetext{
Figure 12. Example of type of S-neuron that was probably an interneuron. This neuron responded to stimulation of the mucosa oral to the recording site with an intermittent burst of small fast EPSPs. $A$ is a low-power drawing showing the entire extent of the biocytin-injected neuron that could be followed in the preparation; the stippled areas show the primary plexus and parts of the myenteric ganglia through which the axon passed (oral is at the top of the figure). The axon of this neuron gave rise to a series of side branches in the ganglia that are shown at higher power in $B-F . B$ shows a camera lucida drawing of the first spray of endings, and $C$, a micrograph of the same area. It can be seen from the micrograph that the endings in the spray were varicose. $D$ shows a small side branch consisting of 2 very short varicose arms that may have contacted a single myenteric neuron. $E$ and $F$ show more extensively branching collaterals in 2 ganglia that were farther from the cell body; these collaterals were also varicose (not illustrated). $G$ and $H$ are a camera lucida drawing and a micrograph showing the cell body of this neuron, which had many filamentous dendrites.
}

Figure 13. Example of morphology and projections of neurons that supplied tertiary plexus. $A$ shows a low-power camera lucida drawing of the full extent of the biocytin-injected neuron; the axon branched extensively within the tertiary plexus, and, though not illustrated in the low-power drawing, all branches were varicose. This can be seen clearly in the high-power drawing of the cell body and proximal axon branches shown in $B$. $C$ shows a neuron that responded to mechanical stimulation of the mucosa oral to the point of recording with a burst of fast EPSPs. The dots indicate the electrical artifacts associated with lowering and raising the mechanical brush. 


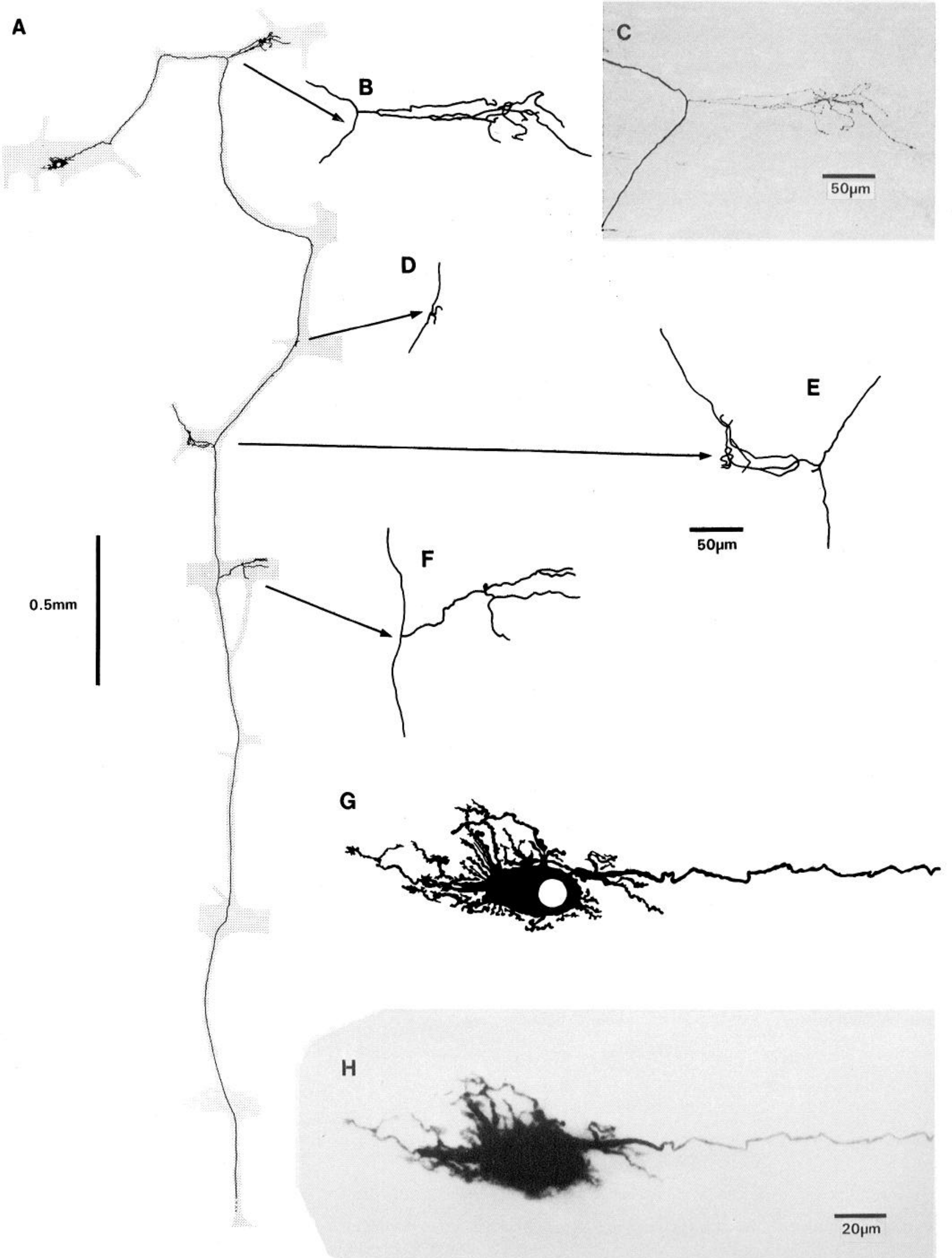




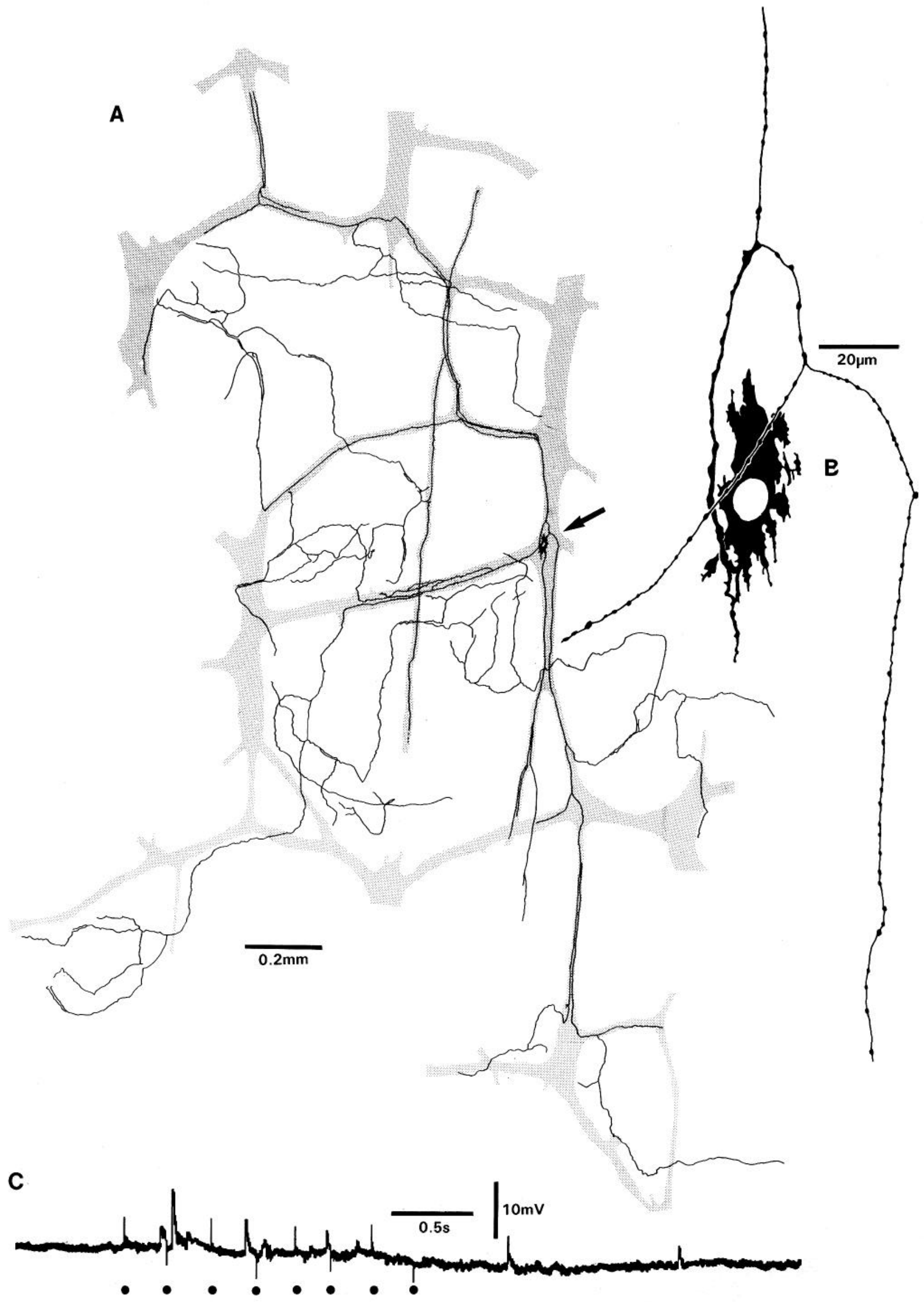


Figure 14. Schematic drawing illustrating basic circuit deduced from this and previous studies to mediate mucosa-to-muscle reflexes. Although the ascending and descending pathways appear to involve different neurons, each pathway is probably similar to the other in general form. The sensory neurons are deduced to project $2-3 \mathrm{~mm}$ around the intestine, making contact with excitatory interneurons that project along the intestine to innervate longitudinal muscle motor neurons, circular muscle motor neurons, and other longitudinally projecting interneurons. The circular muscle motor neurons have a substantial projection around the intestine, perhaps up to half the circumference; the tertiary plexus neurons innervate a region close to their cell bodies. All the cell bodies lie in the myenteric plexus; the sensory neurons are $\mathrm{AH}$-neurons, and the interneurons and motor neurons are $\mathrm{S}$-neurons.

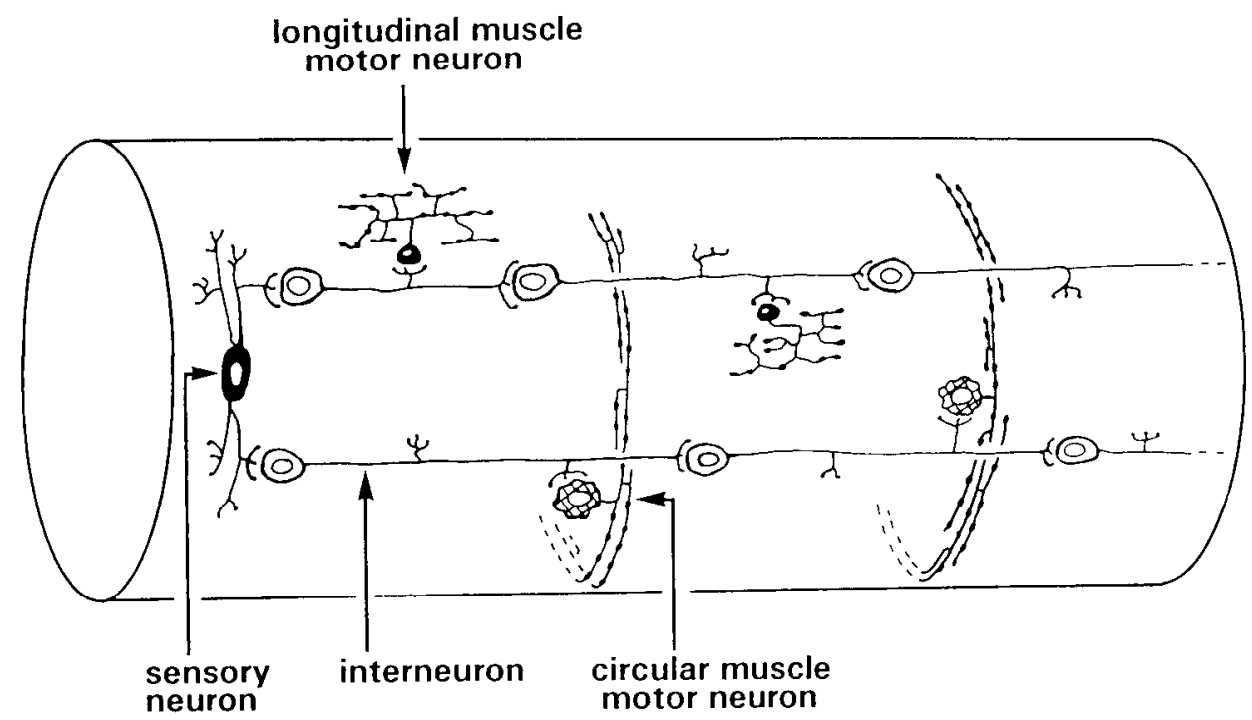

EPSPs or a slower depolarization. This suggests that the cell bodies of the primary sensory neurons were closer to the stimulus than those of the impaled neurons. That is, the sensory processes do not extend more than about $5 \mathrm{~mm}$ (the minimum separation between the recording site and the region of mucosa that was stimulated) along the intestine. Primary sensory neurons impaled at greater distances from the site of stimulation would therefore be expected to remain unresponsive to mucosal stimulation. They would respond only if they received modifying inputs from reflexes evoked in adjaccnt regions. In fact, changes in membrane potential were observed in only 2 of 48 AH-neurons. These neurons all have the shape of Dogiel type II neurons (see Fig. 4; Bornstein et al., 1984; Erde et al., 1985; Katayama et al., 1986; Iyer et al., 1988), which were suggested by Dogiel (1899) to be enteric sensory neurons. More recent workers have also proposed that the AH/Dogiel type II neurons are primary sensory neurons (see Pompolo et al., 1989; Furness and Bornstein, 1991). Most of these neurons have processes in the mucosa that could detect mechanical stimuli (Furness et al., 1990 ), and they have other processes that run circumferentially to provide synaptic inputs to other myenteric neurons (Pompolo and Furness, 1988; J. C. Bornstein, R. Hendriks, J. B. Furness, and D. C. Trussell, unpublished observations). The cell bodies of most AH-neurons are in myenteric ganglia almost directly above their mucosal projections (Furness et al., 1990). It is thus not surprising that few of the AH-neurons, which were a minimum of $5 \mathrm{~mm}$ from the stimulus, showed direct response to mucosal stimulation. AH/Dogiel type II neurons extend their output processes 2-3 $\mathrm{mm}$ around the circumference of the intestine, but almost always less than $2 \mathrm{~mm}(0.5-1 \mathrm{~mm})$ along the intestine (Furness et al., 1990; Hendriks et al., 1990; J. C. Bornstein, R. Hendriks, J. B. Furness, and D. C. Trussell, unpublished observations).

The great majority of neurons that were excited by mucosal stimulation were $\mathrm{S}$-neurons, indicating that the interneurons and motor neurons are S-neurons. This was confirmed by examining the projections of the S-neurons that had been injected with biocytin. These neurons all had a single long process that could be an axon. Some of these axons ran longitudinally within the myenteric plexus and supplied varicose branches to ganglia along their course. This provides direct evidence that some of the S/uniaxonal neurons are interneurons. The axons of the interneurons ran longitudinally and had little circumferential projection. Other $\mathrm{S} /$ uniaxonal neurons projected into the tertiary plexus and were presumably motor neurons innervating the longitudinal muscle. Most of the S/uniaxonal neurons, however, appeared to project into the circular muscle either near their cell bodies or after projecting for some distance along the intestine. These neurons presumably include the motor neurons innervating the circular muscle, but may also include neurons whose targets are in the submucosa, the muscularis mucosae, or the mucosa.

In normal circumstances, the intestine contracts or relaxes as a ring, indicating that reflex responses can propagate around the intestine. The predominantly longitudinal projections of the interneurons suggest that the circumferential spread of reflex activity is not a result of the projections of interneurons. The only neurons found to have significant circumferential projections were AH/Dogiel type II neurons (Hendriks et al., 1990; Bornstein, Hendriks, Furness, and Trussell, unpublished observations) and some of the S/uniaxonal neurons that appeared to enter the circular muscle. It has been estimated that the motor neurons to the circular muscle extend up to halfway around the intestinal circumference after they enter the muscle layer (Bornstein ct al., 1986; Smith ct al., 1988). Thus, reflexes can spread over a considerable proportion of the circumference of the intestine as a result of the projections of the sensory neurons within the myenteric plexus and the projections of the motor neurons within the circular muscle.

These results suggest that the general arrangement of a mucosal reflex pathway is similar to that shown in Figure 14. Sensory neurons located close to the point of stimulation extend output processes around the intestine to contact interneurons that run along the length of the intestine to contact tertiary plexus neurons, circular muscle motor neurons, and other longitudinally projecting interneurons. Both the ascending and the descending pathways appear to be organized in this way.

The majority of the interneurons in each reflex pathway are 
probably cholinergic. AH/Dogiel type II neurons project only 0.5-1 mm along the intestine (Furness et al., 1990; Hendriks et al., 1990; Bornstein, Hendriks, Furness, and Trussell, unpublished observations), so the distance between the sensory neurons and the recording sites could only be bridged by 1 or more interneurons. It is these interneurons that must have been responsible for the fast EPSPs recorded in response to mucosal stimulation, and the fast EPSPs are known to be due to the action of ACh on nicotinic receptors (Nishi and North, 1973; Hirst et al., 1974).

\section{Convergence of pathways}

Detailed analysis of the responses evoked by mucosal stimulation indicates that the circuit shown in Figure 14 can be extended in a number of ways. For example, the analysis of the amplitudes and latencies of the individual fast EPSPs making up the response to a single stimulus indicates that most neurons received inputs from at least 2 or 3 neurons in the pathways. The exact number of converging inputs could not be determined from the amplitude distributions because the contribution of factors such as quantal fluctuation was impossible to estimate.

The stimulus in these experiments would be expected to activate sensory neurons at steadily increasing distances from the recording site. This may explain the wide spread of latencies of the fast EPSPs evoked during a response. However, this implies that the outputs of several sensory neurons located at different sites along the intestine converge, via interneurons, on a single neuron. This suggests that the interneurons represent a common pathway for the reflexes evoked at many different sites. Interneurons would therefore receive inputs from local sensory neurons, from nearby interneurons in the pathway, and from more distant neurons in the pathway. The interneurons identified in this study all had collaterals in ganglia close to their cell bodies as well as making more distant contacts.

The results also suggest that the ascending and descending pathways may converge onto the same neurons in certain cases. Almost all the filamentous and small neurons tested in the descending pathway responded, and about $70 \%$ of such neurons tested in the ascending pathway also responded (Table 2). Thus, some of the filamentous or small neurons may be common to both the ascending and the descending pathways. Because neurons with these shapes often appeared to have relatively short projections entering the circular muscle, it is possible that the pathways converge onto some of the final motor neurons projecting to this layer. This is consistent with the observation that both mucosal stimulation and distension can sometimes evoke an inhibitory junction potential in the circular muscle on the oral side of a stimulus (Smith and Furness, 1988; Smith et al., 1990). It is also consistent with the conclusion of Hirst et al. (1975) that distension can cause excitation of the circular muscle on the anal side of the stimulus.

It is also possible that some $S$ /uniaxonal neurons are not part of the reflex pathways examined in these experiments. The proportion of Dogicl type I neurons that responded to the mucosal stimulation was significantly less than that of the other S/uniaxonal neurons. Of the Dogiel type I neurons that did not respond, nearly all had long anally directed projections, consistent with the suggestion that neurons of this shape are inhibitory motor neurons with long projections to the circular muscle (Furness et al., 1988). The long inhibitory motor neurons project up to 12-25 mm along the intestine before ending in the muscle (Bornstein et al., 1986). Thus, if these neurons receive direct input from the sensory neurons, they could make a substantial contribution to a descending reflex even if they received minimal input from the interneurons of the reflex pathways. In this case, substantial responses would only be recorded in the long inhibitory motor neurons when the recordings were made within the region covered by a sensory neuron $(1 \mathrm{~mm}$ or less along the intestine from the point stimulated).

\section{Dynamic properties of the reflexes}

The majority of the S/uniaxonal neurons that responded exhibited bursts of 4-20 fast EPSPs in response to the first stimulus in a train. The mean frequencies of these fast EPSPs were typically between 15 and $40 \mathrm{~Hz}$, though much higher instantaneous frequencies were observed. In a few cells (e.g., Fig. $2 A$ ), fast EPSPs could bc obscrved scveral seconds after the end of stimulus, but, in most, the bursts lasted less than $0.5 \mathrm{sec}$. These bursts were probably due to repeated activation of several converging interneurons. When the fast EPSPs in a burst reached threshold, either because the fast EPSPs themselves were suprathreshold or because of summation of different inputs, the responding neurons could fire action potentials at substantial frequencies. For example, the neuron illustrated in Figures $6 \mathrm{~A}$ and $9 A$ averaged nearly 3 action potentials per initial stimulus, with a mean frequency greater than $10 \mathrm{~Hz}$ (the mode was nearly $20 \mathrm{~Hz}$ ). The frequency of the action potentials in this neuron was sometimes as high as $100 \mathrm{~Hz}$. Thus, during reflexes, rates of firing of $10-20 \mathrm{~Hz}$ may be expected in individual interneurons and motor neurons.

The latencies of responses recorded in these preparations varied substantially both between trials and within trials (see Fig. 8). This may have been due to a combination of several factors, including the low conduction velocity in the pathway (about $0.05 \mathrm{~m} / \mathrm{sec}$ or less) and a need for convergence of sensory input onto the interneurons before transmission along the pathway can be initiated. Nevertheless, the latency distributions for fast EPSPs with characteristic amplitudes were sometimes multimodal (e.g., Fig. 8A), supporting the idea that individual interneurons closer to the stimulus were excited several times by the same stimulus.

The responses recorded during repeated mucosal stimulation show some important parallels with the results of Smith and Furness (1988) on the reflex responses evoked in the circular muscle by mucosal stimulation. They found that the excitatory junction potentials evoked by stimulation of the ascending mucosal reflex pathway declined markedly with repeated stimulation. A similar effect can be seen in the interneurons and motor neurons of the ascending pathway (Fig. 5). Furthermore, the results imply that the decline is due to a failure to initiate action potentials in the interneurons that lie between the sensory neurons and the recording site. This may be due to a decline in the firing of the sensory neurons or to a failure of synaptic transmission from the sensory neurons to nearby interneurons.

The descending inhibitory response recorded in the circular muscle also declined with repeated stimulation, but this decline was less marked than that of the ascending excitatory response (Smith and Furness, 1988). Small inhibitory junction potentials could often be recorded during prolonged stimulation. The decline of the responses recorded in neurons of the descending pathway was also less marked than that seen in the ascending pathway (cf. Figs. 5, 6); fast EPSPs and action potentials could still be evoked even after 20 stimuli. That is, at a time when the ascending pathway is no longer active, the descending path- 
way is still receiving a significant input. This suggests that the site of the decline in activation of the pathways is probably close to the point at which the pathways diverge. Either each pathway includes separate sensory neurons with differing responses to repeated stimuli, or the outputs of a common sensory neuron to interneurons in the pathways have distinctly different properties for each pathway. The present results do not allow these 2 possibilities to be distinguished.

The results of this study indicate that the neural circuitry mediating the reflex responses of the guinea-pig small intestine to mechanical stimulation of the mucosa can be divided into ascending and descending pathways. Although these pathways may converge onto some final motor neurons, most neurons in the pathways probably receive powerful input only from local sensory neurons and longitudinally projecting interneurons of their own pathway. A very large proportion of the S/uniaxonal neurons responded to mucosal stimulation, suggesting that most of these neurons take part in mucosa-to-muscle reflexes. Hirst et al. (1975) reported that more than $90 \%$ of the S-neurons they studied responded to distension of a segment of intestine lying oral to the site of recording. Thus, it is likely that many of the $\mathrm{S}$ /uniaxonal neurons in the mucosal reflex pathway, perhaps including some in the ascending pathway, are also in a distension-activated descending reflex pathway. However, studies of mucosal reflexes and distension reflexes recorded in the circular muscle indicate that different sensory neurons may mediate the 2 responses (Smith and Furness, 1988; Smith et al., 1990). Distension of the intestine in vivo would be expected to simultaneously deform the mucosal villi, hence mechanically stimulating the mucosa; thus, it is of interest that the 2 different types of stimuli may activate common motor neurons.

\section{References}

Bayliss WM, Starling EH (1899) The movements and innervation of the small intestine. J Physiol (Lond) 24:100-143.

Bornstein JC, Costa M, Furness JB, Lees GM (1984) Electrophysiology and enkephalin immunoreactivity of identified myenteric plexus neurones in the guinea-pig small intestine. J Physiol (Lond) 351:313325.

Bornstein JC, Costa M, Furness JB, Lang RJ (1986) Electrophysiological analysis of projections of enteric inhibitory motor neurones in the guinea-pig small intestine. J Physiol (Lond) 370:61-74.

Dogiel AS (1899) Ueber den Bau der Ganglien in den Geflechten des Darmes und der Gallenblase des Menschen und der Säugetiere. Arch Anat Physiol (Leipzig) 1899:130-158.

Erde SM, Sherman D, Gershon MD (1985) Morphology and serotonergic innervation of physiologically identified submucous neurons of guinea-pig's myenteric plexus. J Neurosci 5:617-633.

Furness JB, Bornstein JC (1991) The enteric nervous system and its extrinsic connections. In: Textbook of gastroenterology (Yamada $\mathrm{T}$, ed). Philadelphia: Lippincott, in press.

Furness JB, Costa M (1987) The enteric nervous system. New York: Churchill Livingston.

Furness JB, Llewellyn-Smith IJ, Bornstein JC, Costa M (1988a) Chemical neuroanatomy and the analysis of neuronal circuitry in the enteric nervous system. In: Handbook of chemical neuroanatomy, Vol 6 , The peripheral nervous system (Björklund A, Hökfelt T, Owman C, eds), pp 161-218. Amsterdam: Elsevier.

Furness JB, Bornstein JC, Trussell DC (1988b) Shapes of nerve cells in the myenteric plexus of the guinea-pig small intestine revealed by the intracellular injection of dye. Cell Tissue Res 254:561-571.

Furness JB, Trussell DC, Pompolo S, Bornstein JC, Smith TK (1990) Calbindin neurons of the guinea-pig small intestine: quantitative analysis of their numbers and projections. Cell Tissue Res 260:262-272.

Hendriks R, Bornstein JC, Furness JB (1990) An electrophysiological study of the projections of putative sensory neurons within the myenteric plexus of the guinea-pig ileum. Neurosci Lett 110:286-290.

Hirst GDS, McKirdy HC (1974) A nervous mechanism for descending inhibition in guinea-pig small intestine. J Physiol (Lond) 238:129_ 143.

Hirst GDS, Holman ME, Spence I (1974) Two types of neurones in the myenteric plexus of duodenum in the guinea-pig. J Physiol (Lond) 236:303-326.

Hirst GDS, Holman ME, McKirdy HC (1975) Two descending nerve pathways activated by distension of guinea-pig small intestine. J Physiol (Lond) 244:113-127.

Hodgkiss JP, Lees GM (1983) Morphological studies of electrophysiologically identified myenteric plexus neurons of the guinea-pig ileum. Neuroscience 8:593-608.

Horikawa K, Armstrong WE (1988) A versatile means of intracellular labeling: injection of biocytin and its detection with avidin conjugates. J Neurosci Meth 25:1-11.

Iyer V, Bornstein JC, Costa M, Furness JB, Takahashi Y, Iwanaga T (1988) Electrophysiology of guinea-pig myenteric neurons correlated with immunoreactivity for calcium binding proteins. J Auton Nerv Syst 22:141-150.

Katayama Y, Lees GM, Pearson GT (1986) Electrophysiological and morphological characteristics of vasoactive intestinal peptide (VIP)immunoreactive neurones in the guinea-pig myenteric plexus. J Physiol (Lond) 378:1-11.

Mall F (1896) A study of the intestinal contraction. John Hopkins Hosp Rep 1:37-75.

Nishi S, North RA (1973) Intracellular recording from the myenteric plexus of the guinea-pig ileum. J Physiol (Lond) 231:471-491.

Nothnagel H (1882) Zur chemischen Reizung der glatten Muskeln; zugleich als Beitrag zur Physiologie des Darmes. Arch Path Anat Physiol Klin Med 88:1-11.

Pompolo S, Furness JB (1988) Ultrastructure and synaptic relationships of calbindin-reactive, Dogiel type II neurons, in myenteric ganglia of guinea-pig small intestine. J Neurocytol 17:771-782.

Pompolo S, Furness JB, Bornstein JC, Iendriks R, Trussell DC (1989) Dogiel type II neurons in the guinea-pig small intestine: ultrastructure in relation to other characteristics. In: Nerves in the gastrointestinal tract (Singer MV, Goebell H, eds), pp 57-67. Lancaster: Kluwer Academic.

Smith TK, Furness JB (1988) Reflex changes in circular muscle activity elicited by stroking the muscosa: an electrophysiological analysis in the isolated guinea-pig. J Auton Nerv Syst 25:205-218.

Smith TK, Furness JB, Costa M, Bornstein JC (1988) An electrophysiological study of the projections of motor neurones that mediate non-cholinergic excitation in the circular muscle of the guinea-pig small intestine. J Auton Nerv Syst 22:115-128.

Smith TK, Bornstein JC, Furness JB (1990) Distension-evoked ascending and descending reflexes in the circular muscle of guinea-pig ileum: an intracellular study. J Auton Nerv Syst 29:203-213.

Stach W (1989) A revised morphological classification of neurons in the enteric nervous system. In: Nerves and the gastrointestinal tract (Singer MV, Goebell H, eds), pp 29-45. Lancaster: Kluwer Academic. 